\title{
From Parametric Design to Contour Crafting Technics: A Lab for Algo+Ritmo, a Brazilian Research Group
}

\author{
Natália de Andrade Corrêa \\ UFMS | Brasil | nateandracor@hotmail.com \\ Gilfranco Medeiros Alves \\ UFMS | Brasil | gilfranco.alves@ufms.br
}

\begin{abstract}
This article presents a discussion on digital design processes. More precisely about the use of Contour Crafting (CC) as a material and technique solution for the construction which will carry less impact for the environment. It explores the connection between parametric process and the file-to-factory concept analyzing the consequences of those strategies. The paper describes and analyzes a case study starting from the demand for a headquarters project for a university research group. It presents possibilities and discusses futures developments based on the methodology used in the process.
\end{abstract}

Keywords: Digital Fabrication; Design Process, File-to-factory; Contour Crafting; Algorithm.

\section{INTRODUÇÃO}

O objeto de estudo deste artigo é a discussão de fundamentos envolvendo a aplicação de processos digitais de projeto e de fabricação digital, a partir do desenvolvimento de pesquisa teórica relacionada especialmente à bioinspiração e à técnica de Contour Crafting (CC), produzindo ao final do processo um projeto arquitetônico para sediar o grupo de pesquisa Algo+Ritmo da Universidade Federal de Mato Grosso do Sul, que servirá de estudo de caso e de retroalimentação entre teoria e prática.

O grupo de pesquisa criado em 2013, junto ao Curso de Arquitetura e Urbanismo da UFMS, possui conexão com outros grupos e pesquisadores de diversos níveis, e desenvolve investigações sobre o tema do processo de projeto e o uso de meios digitais nas linhas de pesquisa: 1. Processos de Projeto, na qual se estudam os processos de projeto e design envolvidos na construção das espacialidades híbridas, concretas e virtuais; 2. Processos de Comunicação, que procuram compreender a comunicação de diferentes naturezas e processos de ensino e aprendizado intermediados por sistemas informatizados; e 3. Processos de Produção, que envolvem a atualização e utilização das tecnologias de produção contemporâneas em experimentações de natureza prática, especialmente, prototipagem e fabricação digital.

A ausência de espaço físico para uso do grupo com infraestrutura que atenda às necessidades de todas as atividades realizadas, fez surgir a demanda de um possivel prédio para fomentar a pesquisa, atrair pessoas de outras áreas e cidades, ministrar workshops, capacitar pesquisadores e a população em geral, além de buscar conscientizar sobre as tecnologias e práticas inovadoras, fomentar outros projetos e criar trocas de conhecimentos em diversas escalas, promovendo retroalimentação de conhecimento para o grupo, para o curso, para a Universidade e para toda a sociedade, em amplo senso.

O desafio central foi a elaboração de um projeto arquitetônico no qual fundamentações teóricas e experiências práticas estudadas fossem aplicadas em todo o processo, resultando em um espaço no qual os usuários pudessem observar, experienciar e compartilhar integralmente os principais conceitos investigados pelo grupo, bem como apresentar de modo transparente todo o processo de projeto até sua execução. Como estratégia de produção, a técnica construtiva de Contour Crafting foi proposta por sua base na fabricação digital e sua essência file-to-factory. O uso do equipamento em questão foi idealizado propositadamente para ser agregado ao inventário de equipamentos do grupo, bem como o acompanhamento da obra por parte dos futuros pesquisadores. Tal estratégia implica diretamente na retroalimentação de conhecimentos do grupo, enriquecendo o processo em questão, e pesquisas futuras. Durante o desenvolvimento do projeto, as temáticas abordadas foram relacionadas a bioinspiração e morfogênese digital, design generativo, parametrização, fabricação digital e prototipagem, com foco nas técnicas de Contour Crafting.

O presente artigo, portanto, busca discutir vantagens no uso desta tecnologia e sua relevância para o futuro da arquitetura e design, assim como sua relação direta com a temática principal a ser discutida neste congresso, ou seja, o projeto transformador e seu papel insubstituível no design e arquitetura. Acredita-se que a relevância do projeto reside na elaboração de um desenho arquitetônico atual, com fundamentação teórica que se utiliza de processos digitais para a geração de infinitas possibilidades, e cujos resultados obtidos são diretamente 
influenciados pelas escolhas dos projetistas definidas pela parametrização. No mesmo sentido, a escolha da técnica construtiva associada a fabricação digital, o uso de materiais renováveis e a imersão na temática do Contour Crafting são vitais para explorar, analisar e aperfeiçoar essa possibilidade como alternativa para processos de produção da arquitetura de modo mais integrado com a natureza e menos impactante para o meio ambiente.

\section{METODOLOGIA}

A metodologia partiu da premissa da retroalimentação entre teoria e prática, visando a evolução do design e dos conceitos que passam a ser (re)significados a cada rodada de atualizações. O embasamento teórico buscou definir os conceitos básicos que serviram como referência sobre processos digitais de projeto, concentrando-se nas características da bioinspiração digital e nas técnicas de Contour Crafting, dentre outros. As referências fundamentaram os estudos através de diagramas, croquis, diretrizes, análises, volumetrias e simulações. $\mathrm{Na}$ sequência, os estudos volumétricos foram sendo desenvolvidos levando em consideração a técnica construtiva a ser empregada. O pré-dimensionamento (espacial e estrutural) foi realizado através de parâmetros estabelecidos pelo script Metaball (desenvolvido no plugin Grasshopper), essencial para direcionar o form-finding da edificação, bem como as soluções técnicas adotadas. A estética objetivada buscou a atualização da linguagem construtiva a ser utilizada no Campus para o qual a edificação foi projetada, de modo a provocar reflexões sobre as possíveis transformações que o design pode trazer e as vantagens que as escolhas metodológicas proporcionaram ao processo.

\section{RESULTADOS}

A revisão bibliográfica foi realizada ao longo do trabalho, contemplando conceitos arquitetônicos relacionados principalmente com a natureza, processos de fabricação digital e a conexão do projetista com os meios de fabricação. A materialização do modelo virtual para o objeto real através do procedimento file-to-factory (arquivopara-fabricação), será abordada, assim como trataremos de que forma os conceitos estudados foram empregados no projeto arquitetônico. A discussão sobre a relevância de ambas as instâncias, especialmente no que é relacionado ao equilíbrio sistêmico e retroalimentação de ambas (feedback looping cibernético), será tratado a seguir, em desdobramentos teóricos (a) e projetuais (b):

\section{(A)TEÓRICOS}

Um dos primeiros conceitos levados em consideração foi o da bioinspiração, especialmente 0 da biomimética (Biomimicry). As vantagens, características, formas e funções advindas das estruturas bio-inspiradas, e sua essência interdisciplinar, levaram a estudos sobre a relevância de se agregar conceitos e ensinamentos da natureza, e de certo modo, propor releituras, muito mais do que propor soluções inéditas.

"A Biomimética é essencialmente interdisciplinar, uma série de colaborações e trocas entre matemáticos, físicos, engenheiros, botânicos, médicos e zoólogos. As rígidas fronteiras entre a taxonomia herdada de disciplinas "puras" fazem pouco sentido neste novo território. Da mesma maneira, as formas tradicionais da arquitetura e engenharia de pensar em materiais como algo independente da forma e estrutura estão obsoletas." (Weinstock, 2006, p. 36, tradução livre)

A natureza faz uso econômico de materiais através da ausência do supérfluo, o refinamento estrutural seleciona as estruturas mais resistentes e econômicas. Mecanismos digitais foram criados inspirando-se na lógica da natureza. Por meio desses, é possível simular o desempenho estrutural natural de maneira autêntica, gerando rapidamente estruturas complexas, ao longo do processo de form-finding. Inicialmente o computador servia apenas para representação de projetos, e posteriormente, foi incorporado ao processo de projeto em si a fim de gerar a forma e simular comportamentos. Tal processo por meios digitais vem atualizando o modo como os projetistas abordam o design, focando cada vez mais em estratégias a partir de scripts que otimizam as performances geométricas, estruturais, e de conforto ambiental, entre outros, e libertando nossa mente para focar no desenvolvimento criativo (Vincent, 2002; Kolarevic, 2003; Kotnik, 2006; Terzidis, 2006; Leach, 2009; Tedeschi, 2011; Roudavsky, 2012).

A fabricação digital, por exemplo, associa a ação e a visualização projetual, possibilitando que o projetista se reconecte com os meios de produção, de modo mais experimental e explorando mais a prototipagem como método. A ampliação de suas técnicas (aditivas, subtrativas, formativas e por montagem robótica) possibilitou o desenvolvimento de formas mais inovadoras e complexas de maneira econômica e eficiente, outrora inviáveis através de técnicas tradicionais. Sua complexidade se baseia em regras simples, sendo justamente em sua simplicidade conceitual que reside a beleza e a riqueza do processo (Tedeschi, 2011; Sperling, 2003; Stacey, 2004; Orciuoli; Celani, 2010; Oosterhuis apud Alves, 2014).

Esse contexto, no qual nos encontramos a partir das tecnologias e processos acima comentados, viabilizou a personalização em massa integrada à indústria 4.0. Podemos variar os parâmetros aprimorando e diferenciando os itens ao longo da produção, mantendo o tempo e quantidade de material constantes. Desta maneira, a razão para produção em série de itens idênticos, torna-se ultrapassada. Mas existe, ainda, um longo caminho de aprimoramento a ser percorrido no âmbito da comunicação entre o design digital e sua execução em si (Estevez, 2003; Stacey, 2004; Oosterhuis apud Alves, 2014).

"Como as variações podem ser automatizadas, a máquina não se importa em fazer 100 peças todas iguais ou 100 todas diferentes, já que elas têm o mesmo custo sendo iguais ou diferentes, chegou-se ao fim um dos maiores mitos da modernidade, a produção em série uniforme. [...] Objetos clássicos no passado foram feitos um por um, à mão. Objetos modernos no presente são feitos em série, em uma máquina, tudo a mesma coisa. Os objetos genéticos no futuro também serão automatizados, mas todos diferentes" (Estevez, 2003, p. irreg., tradução livre) 

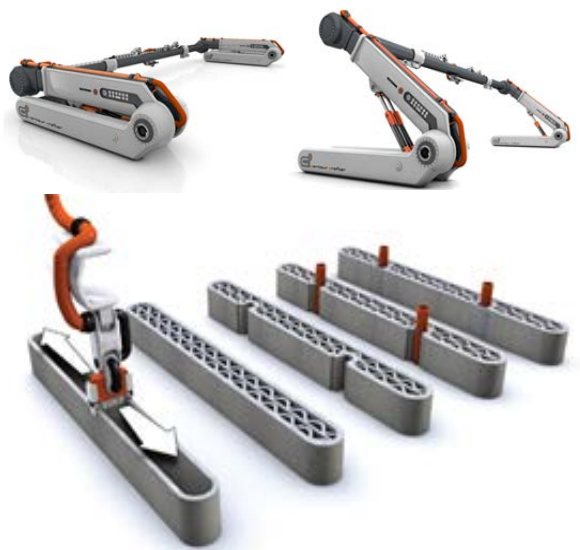

Figura 1: Equipamento de Contour Crafting retraído e aberto, $e$ o bico extrusor imprimindo estruturas em concreto. Fonte: Bertram, S. 2011

A prototipagem rápida é a execução física do design digital em pequena escala por equipamentos como CNCs, impressoras 3D, cortadoras à laser e braços robóticos. Viabiliza a passagem da ideia de modelos em estudo para um objeto real em um curto período de tempo, justamente por permitir a atualização constante do modelo digital, sendo ideal para testar, aprimorar, e evoluir o projeto. (Tedeschi 2011; Alves 2014). Esse processo também é chamado de file-to-factory, onde o arquivo com o design produzido transforma-se em código diretamente dos modelos 3D digitais a ser compreendido pelos equipamentos de fabricação. Esse arquivo é essencial para gerar as linhas de corte, camadas de impressão, e percursos de movimentação. (Stacey, 2004; Fernandes, Feitosa, 2015).

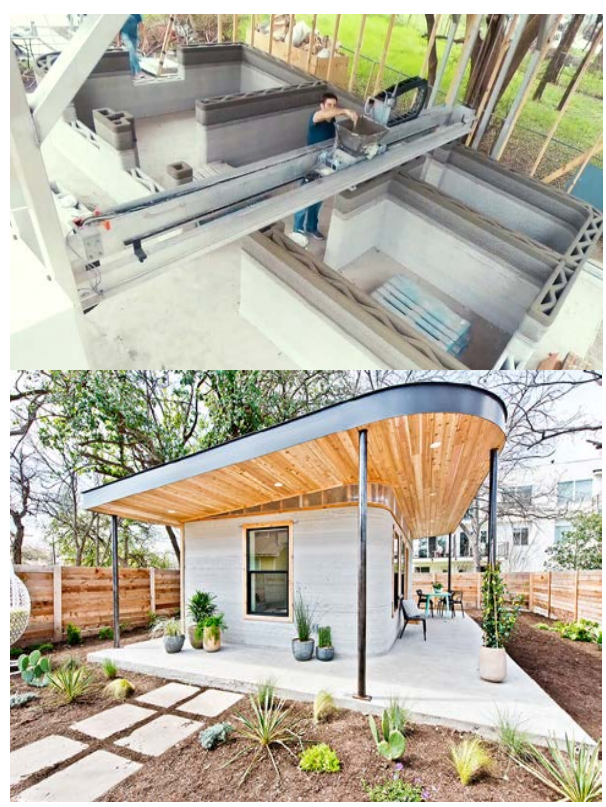

Figura 2: a. Equipamento de CC imprimindo habitações em concreto para uma vila inteira; b. Habitação finalizada com moradores. Fonte: New Story Charity, 2020.
O real processo a ser percorrido pode ser camuflado pela simplicidade do termo file-to-factory, entretanto adaptações, correções e outros detalhes importantes precisam ser trabalhados ao longo do processo para a sua correta execução (Orciuoli, Celani, 2010) É de extrema importância que sua implantação inicial no setor se dê através de estudos e modelos em menor escala, facilitando a calibração da técnica. (Stacey, 2004)

A técnica de CC (Figura 1), a qual será nosso foco neste momento do trabalho, trata-se de um processo de fabricação em mega camadas (layered manufacturing), depositando material camada por camada, possibilitando a construção de estruturas sem qualquer tipo de fôrmas. Foi desenvolvida inicialmente por Behrokh Khoshnevis em 1998, utilizando o concreto como matéria prima de seus testes. O equipamento interpreta informações de camadas $2 \mathrm{D}$, combinadas para impressão de um volume 3D. A calibragem, o material escolhido, velocidade de impressão, o nivelamento da superfície de contato, entre outras configurações, são essenciais para que o resultado final ideal seja atingido. Diversos materiais vêm sendo testados de maneira bem-sucedida, como por exemplo concreto, cerâmica, terra, polímeros, vidro, entre outros (Khoshnevis, 2006), (Leach et al, 2012; Fernandes; Feitosa, 2015; Kontovourkis, Tryfonos, 2018).

A indústria da construção começou a explorar o potencial dessa técnica de forma tardia. Projetos e pesquisas recentes mostram sua viabilidade e vantagens, como por exemplo a NASA, explorando a técnica para possíveis construções em outros planetas. (Leach et al, 2012) Alguns exemplos utilizando a técnica foram executados com sucesso nos últimos anos, como a vila no México (2020) idealizada pela New Story (Figura 2) e construída em concreto. (New Story Charity, 2020), e o projeto Gaia

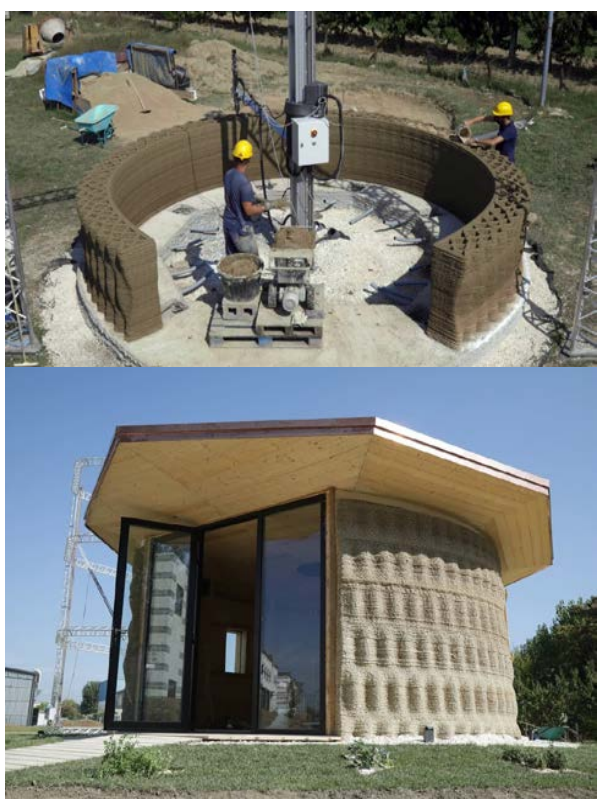

Figura 3: a. Equipamento de CC imprimindo camadas 3D de uma habitação com terra; b. Projeto de habitação Gaia finalizado. Fonte: WASP, 2018 
realizado Itália (2018), elaborado pela WASP (Figura 3) e construída com terra como matéria prima. (Wasp, 2018)

A construção com terra é utilizada em estruturas, principalmente habitações, desde a pré-história. Entretanto, com o passar dos anos, a técnica não acompanhou a industrialização e o desenvolvimento tecnológico do setor, acabou tornando-se pouco utilizada e sinônimo de precariedade, o que consideramos um equívoco. Com a discussão em torno da indústria 4.0, a qual combina máquinas, sistemas, processos inteligentes, o mundo físico e o virtual, inicia-se uma revisão do uso das técnicas com terra na construção civil. Isso se dá devido, principalmente, às preocupações ambientais e com a otimização de recursos.

Após um longo período com usos restritos, ocorre uma ressignificação do material ancestral para alcançar a eficiência almejada na atualidade. A combinação entre o tradicional e o potencial digital ao utilizar a terra associada aos novos equipamentos usados pela indústria 4.0 , pode atender as preocupações da sociedade quanto ao uso de técnicas com menor impacto ambiental possível e menor custo. (Dotta, 2020)

\section{(B) PROJETUAIS}

Além de uma pesquisa de revisão bibliográfica, os resultados incluem o processo de projeto para elaboração de dois edifícios a serem construídos por fabricação em camadas (Layered Manufacturing) através do CC (Figura 4). Sua evolução projetual exemplifica um projeto desenvolvido do começo ao fim por processos digitais, incluindo prototipagem rápida em escala reduzida por impressoras 3D, e das camadas resultantes da técnica construtiva CC. O principal objetivo foi a produção de um espaço que atendesse a demanda do grupo de pesquisa que iria ocupá-lo. Os edifícios também levaram em conta o uso do espaço pelos pesquisadores e suas necessidades específicas, assim como a capacitação de outros estudantes da universidade que pudessem se envolver com a técnica construtiva, e naturalmente, com outras pesquisas e experimentos.

Para alcançar os objetivos, o público alvo (Figura 5) e as diretrizes foram especificadas (Figura 6), gerando um programa de necessidades considerado ideal (Figura 7). 0 local de implantação foi estudado em seu contexto urbano, com análises do entorno, acessos e implantação no contexto da universidade em questão, proximidade a outros grupos de pesquisa e acesso pelos usuários do espaço.

A partir desses condicionantes, o processo de projeto envolveu diagramas, croquis, pré-dimensionamento do edifício, criação de um script gerador da estrutura acompanhado de diversos testes digitais e também prototipagem rápida para estudos estruturais. Foi também deixada em aberto a possibilidade de expansão futura, devido ao espaço residual no terreno, ao fácil acesso à matéria prima local, e à permanência do equipamento em conjunto com pesquisadores capacitados no próprio laboratório.

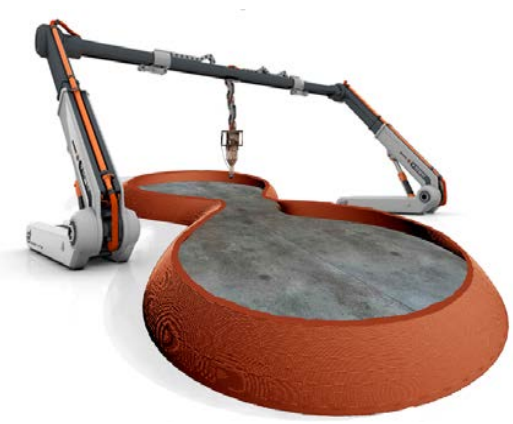

Figura 4: Simulação da técnica de CC na edificação. Fonte:

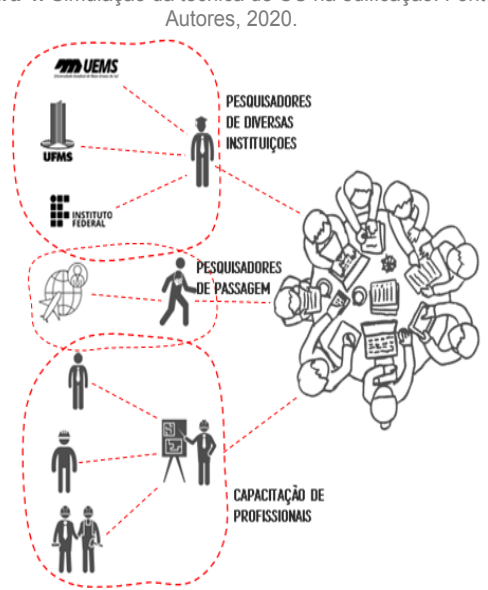

Figura 5: Diagrama de estudo do público alvo. Fonte: Autores, 2019.

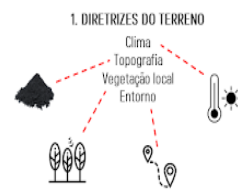

3. DIREIRIZS DE MOBIIDADE

O)

.. Acossibilidade

Acesso por diversos meios -
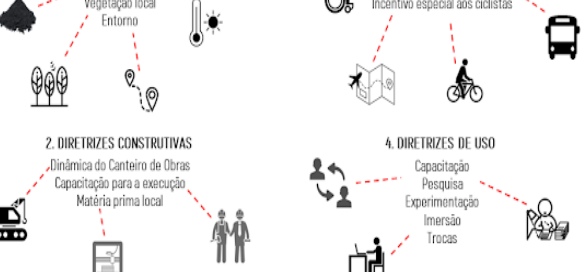

Figura 6: Diretrizes norteadoras do projeto separadas em grupos. Fonte: Autores, 2019.

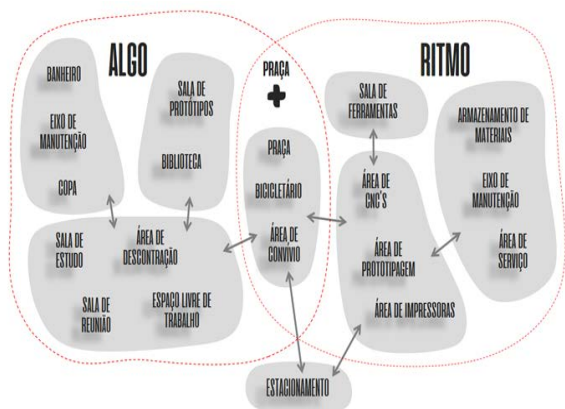

Figura 7: Diagrama de fluxos criados a partir do programa de necessidades (a Imagem foi modificada para manter a identidade do grupo secreta). Fonte: Autores, 2019. 


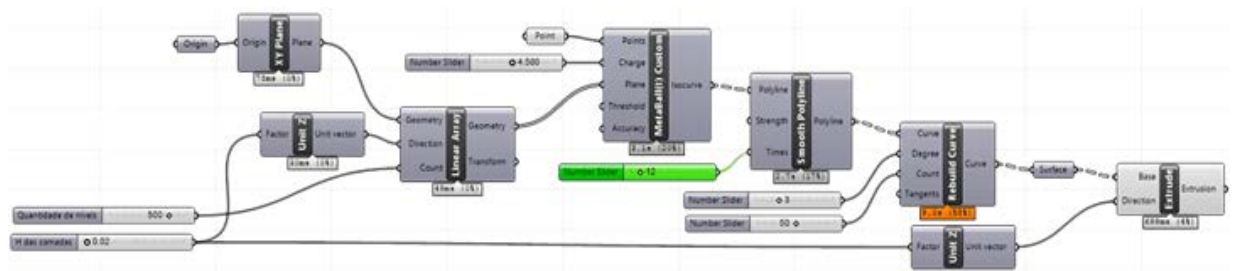

Figura 8: Script Metaball criado no software Grasshopper. Fonte: Autores, 2019.

Ao longo do projeto, foi adotado como bioinspiração o funcionamento do cupinzeiro (Figura 9), suas movimentações de ar internas, buscando atingir um desempenho térmico e estrutural que colocasse em prática as lições de conforto térmico dos interiores dos cupinzeiros. O projeto também explora a lógica do Metaball que pode ser comparado paralelamente ao processo de mitose que ocorre de forma semelhante nas células, no qual podemos visualizar a divisão anterior à divisão completa, num aspecto congelado do processo, ou por exemplo, o momento onde gotas de água estão prestes a se mesclar em uma só. (King et al, 2015). Utilizou-se a fabricação digital e parametrização através do software Rhinoceros e seu plugin Grasshopper, no qual parametrizamos a estrutura pela criação de um script (Figura 8), baseado na lógica do Metaball (Figura 10). Podemos observar alguns dos testes estruturais na Figura 11.

Para testar a estrutura proposta pelo projeto, foi utilizada a técnica de prototipagem rápida (Figura 12). Foi criado um arquivo com as camadas para serem interpretados pela impressora 3D, simulando em pequena escala, a estrutura construída pela técnica de CC. Um modelo inicial da edificação foi impresso pelo equipamento do lab do grupo de pesquisa Algo+Ritmo para testar a viabilidade de tal volumetria na íntegra e ajustar o que se mostrasse necessário.

Esse projeto propõe a combinação entre as duas técnicas, a ancestral construção com terra através dos novos equipamentos de CC desenvolvidos, criando assim uma técnica única de impressão 3D/Layered Manufacturing com camadas compostas principalmente de terra. Buscouse, portanto, integrar o tradicional com tecnologias atuais (high-low), através da programação da estrutura e geração do arquivo que será interpretado pelo equipamento, carregado com a mistura ideal de terra, que ao endurecer

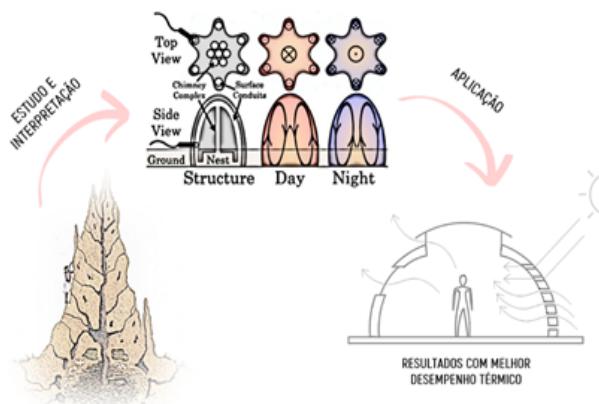

Figura 9: Proposta de ciclo bioinspirado no cupinzeiro, analises e aplicação. Fonte: Autores, 2019, adaptação de King et al, 2015.
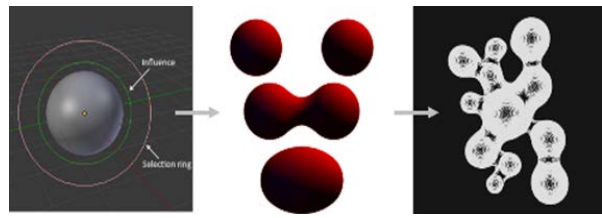

Figura 10: Lógica do script Metaball. Fonte: Autores, 2019
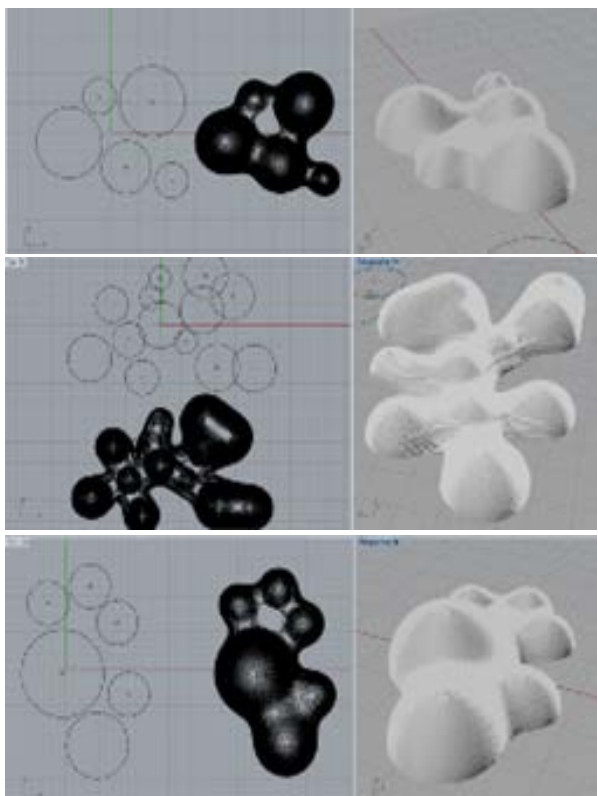

Figura 11: Testes de volumetria no Rhinoceros, utilizando o script desenvolvido no Grasshopper. Fonte: Autores, 2019.

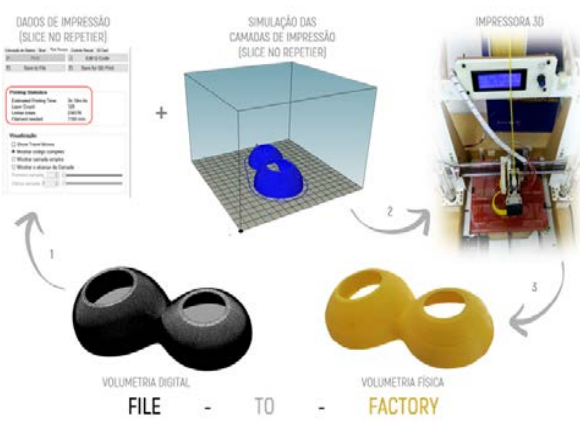

Figura 12: Ciclo do processo de Fabricação Digital até a prototipagem (file-to-factory). Fonte: Autores, 2019. 
se tornará resistente e gerará grande inércia térmica para o conforto ambiental em seu interior. Sua forma originada através da programação Metaball, também foi pensada de acordo com a lógica que o equipamento e a técnica carregam, assim como Leach (2012) ressalta:

"Do ponto de vista estrutural, o processo incentiva formas autossustentáveis durante o processo de construção. Isso implica uma certa lógica 'gótica' de construção que, por exemplo, depende de abóbadas relativamente íngremes e evita o uso de arcos, [...]" (Leach et al, 2012, p. 427, tradução livre)

A construção do projeto, como tratado anteriormente, foi planejada utilizando o CC para impressão das paredes estruturais sobre uma base e início das paredes de concreto, garantindo o afastamento da umidade do solo (Figura 13). As aberturas também seguem a mesma lógica que Leach (2012) comenta, levando em consideração a transferência de forças, e também a necessidade de superfície de contato para a construção das camadas sobre outras camadas. Em seu interior, o script criou ambientes conectados visualmente e de fluxo de passagem fluido entre as meias esferas (Figura 14). Os dois edifícios são interligados por uma pequena praça/pátio para atividades externas (Figura 15).

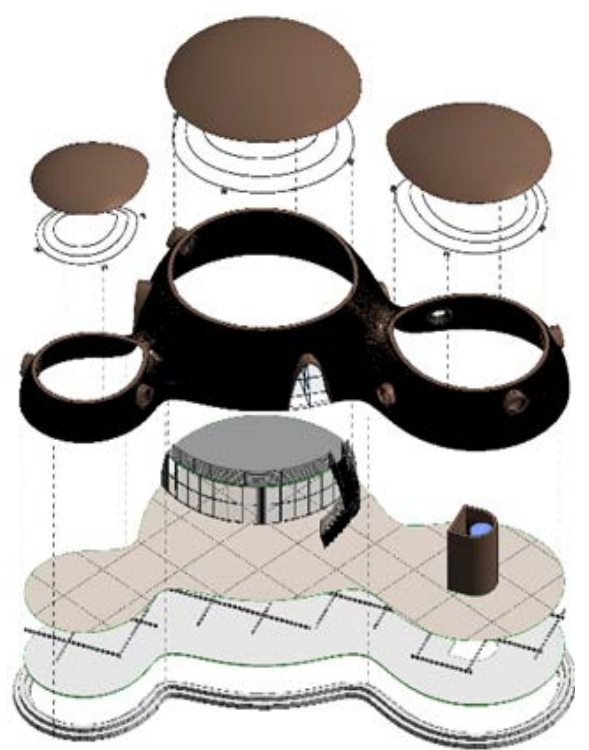

Figura 13: Estrutura do edifício explodida para visualização. Fonte: Autores, 2019

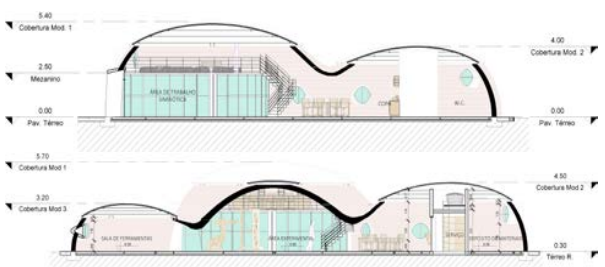

Figura 14: Cortes dos edifícios. Fonte: Autores, 2019.
O processo carrega em seu conceito um caráter autopoiético (Figura 16), pois os equipamentos em questão serão utilizados para construir o edifício sede do grupo de pesquisa, ao mesmo tempo em que este estará em constante observação/teste de validação pelos pesquisadores durante a execução e posteriormente em novos projetos, acarretando uma retroalimentação teórica e prática de conhecimentos e pesquisas para o grupo.

Podemos concluir que, no momento em que se discute uma relação mais amigável para com a natureza, visando combater a escassez de recursos, o impacto da construção no meio ambiente e da permanência das gerações futuras no planeta, destacamos a relevância do processo proposto como alternativa viável. A desaceleração da produção e uma possível redução no processo entrópico a que submetemos os sistemas naturais parece-nos uma alternativa factível, dentro das disponibilidades tecnológicas que os processos digitais nos oferecem atualmente.

\section{DISCUSSÃO}

A discussão da pesquisa e do projeto proposto gira em torno de como o projeto arquitetônico pode ser potencializado através de processos digitais de projeto, a partir de outras tecnologias e técnicas construtivas, voltados para seu desenvolvimento performático, mas sobretudo, menos impactantes para a natureza e, consequentemente, para a própria humanidade. Como seria possível potencializar o pensar arquitetônico através

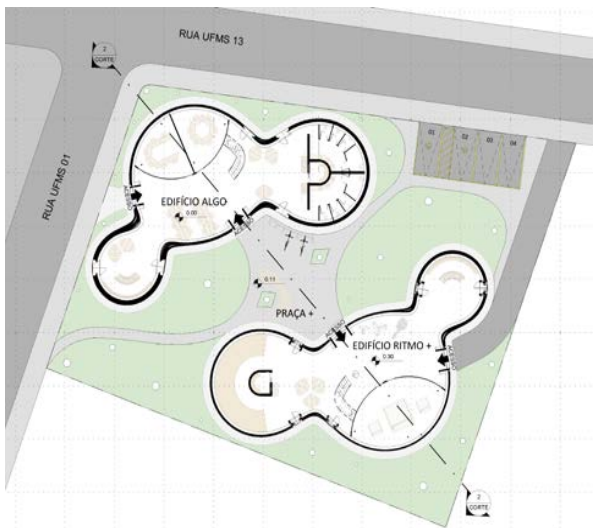

Figura 15: Implantação das edificações. Fonte: Autores, 2019.

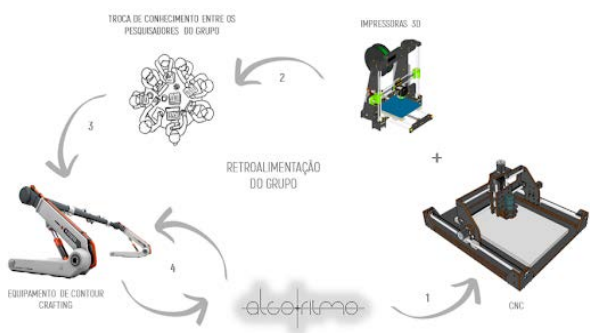

Figura 16: Esquematização do processo de projeto e utilização do espaço proposto, ciclo autopoiético idealizado (A imagem foi modificada para ocultar o nome do grupo). Fonte: Autores, 2019 
das metodologias e processos digitais, suas vantagens e encaminhamentos? Kolarevic propõe:

"Em um afastamento radical das tradições centenárias e das normas do projeto arquitetônico, as formas geradas digitalmente não são projetadas ou desenhadas como o entendimento convencional desses termos teria, mas são calculadas pelo método computacional generativo escolhido. Em vez de modelar uma forma externa, os projetistas articulam uma lógica generativa interna, que então produz, de maneira automática, uma gama de possibilidades a partir da qual o projetista poderia escolher uma proposição formal apropriada para desenvolvimento posterior." (Kolarevic, 2003, p. 13, tradução livre)

É de extrema importância a desmistificação da lenda da genialidade do projetista, explicitando o processo por trás das concepções. Processos de projeto são cheios de erros, acertos e percursos não lineares, com suas idas e vindas para aperfeiçoamento teórico e prático. Para Alexander (1964), toda a superstição em torno da genialidade inerente faz com que poucos realmente busquem o conhecimento do processo de design de forma analítica, e considera que isso ocorre para evitar as inseguranças dos erros que se podem ocorrer, e assim, se manter cercado da inocência presente na criação intuitiva. Comenta que os "designers escondem seu dom em uma pretensão irresponsável ao genial” (Alexander, 1964, p. $11)$, sendo que os projetos de sucesso carregam em si o conhecimento por parte do projetista sobre padrões e semelhanças com outros processos e aspectos que já se provaram eficazes anteriormente.

Os métodos de projeto contemporâneos, que vem empregando cada vez mais as tecnologias digitais, tornaram necessário mudar a maneira como pensamos e como concebemos projetos. Os processos de projeto devem estar em constante evolução, e não estagnar no tempo e repetir procedimentos indefinidamente. Por trás dos processos digitais de projeto existe uma lógica do seu próprio tempo, uma busca por alternativas baseadas em estratégias arquitetônicas mais eficientes e interativas, e não na busca de formas inusitadas, como muitos ainda imaginam. O arquiteto contemporâneo primeiramente define os parâmetros e níveis de colaboratividade que alcançará, gerando infinitas soluções que serão selecionadas de acordo com os objetivos do projeto e dos atores envolvidos. (Kolarevic, 2003; Kotnik, 2010; Roudavsky, 2012).

"Pela primeira vez na história, os arquitetos não estão projetando a forma específica do edifício, mas um conjunto de princípios codificados como uma sequência de equações paramétricas pelas quais instâncias específicas do projeto podem ser geradas e variadas no tempo, conforme necessário. O projeto paramétrico exige a rejeição de soluções fixas e a exploração de potencialidades infinitamente variáveis." (Kolarevic, 2003, p. 18, tradução livre)

Entretanto, a produção teórica na área do projeto digital não vem acompanhando a experimentação prática, em especial no Brasil, onde as pesquisas teóricas tem demonstrado pouca presença na academia e nos currículos da maioria dos cursos de Arquitetura e Urbanismo (Alves, 2014). Isso pode ser a consequência da tradição cultural do gênio criativo, na qual se obteve a partir da arquitetura modernista grande produção e valorização, por sua excelência.

Kotnik (2006) ressalta que a falta de reflexões teóricas repercute direta e negativamente na introdução da temática na grade de ensino de muitas universidades, caso contrário sua produção e discussão seriam fortemente fomentadas. Muito já evoluímos desde suas constatações, entretanto não atingimos o equilíbrio necessário para que os processos digitais de projeto não sejam mais vistos apenas como "ferramentas."

\begin{abstract}
"[...] as tecnologias digitais permitiram novos métodos de design, o que levou a um reexame das teorias atuais de design e conceitos educacionais. Isto é, a arquitetura está participando de uma 'revolução intelectual' que está acontecendo ao nosso redor, mas poucas pessoas estão comentando sobre isso. 0 pensamento computacional está influenciando a pesquisa em quase todas as disciplinas, tanto nas ciências quanto nas humanidades. Está mudando a maneira como pensamos." (Kotnik, 2010, p. 3, tradução livre)
\end{abstract}

Como vimos na seção Resultados, a discussão em torno da técnica de $C C$ na construção civil se mostra ainda muito recente, e explorada tardiamente. A tecnologia traz consigo diversas vantagens para o projeto: (1) gera segurança para os trabalhadores e redução da mão-deobra; (2) pode ser facilmente transportada e utilizado em construções, pesquisas e capacitações futuras, podendo integrar-se com outros métodos construtivos de maneira híbrida; (3) permite utilização de diversos materiais, matéria prima local e com menor desperdício, especialmente com formas; (4) permite criar geometrias complexas com facilidade e se imprimir mais peças de acordo com a necessidade; (5) facilita a construção em locais de difícil acesso, como projetos até mesmo para outros planetas (NASA); (6) proporciona velocidade de fabricação e alta produtividade, em particular para construção de abrigos emergenciais, ou casas completas em apenas 24h, como o exemplo da New Story. (Khoshnevis et al, 2006; Camachoa et al, 2017)

Seu uso com terra local, combinando o tradicional e o tecnológico, resulta em extrema relevância e muitos interesses para o setor. Especialmente no Brasil, percebese uma grande carência relativas às pesquisas e construções associadas à técnica, uma vez que possuímos ainda um enorme déficit habitacional especialmente voltado à questões de demanda social. Acredita-se que a pesquisa e o projeto arquitetônicos desenvolvidos, somados às possibilidades de produção arquitetônica, ofereçam alternativas para produção em maior escala, atendendo as demandas que dizem respeito às necessidades reais da sociedade. Com a escolha pelo Contour Crafting, que pode utilizar a terra como matéria prima, com seus sistemas naturais e caráter renovável, acredita-se que tais estratégias apontam para uma permanência menos agressiva da espécie humana, aceitando seu papel como coabitantes do mesmo planeta, 
simbioticamente. Em um momento tão delicado para o meio ambiente, em todo o mundo, mas, principalmente no Brasil, acredita-se na relevância da discussão proposta, não apenas como método construtivo, mas também por seu caráter educativo para toda a sociedade.

\section{AGRADECIMENTOS}

Agradecemos à UFMS pelas condições oferecidas ao desenvolvimento deste trabalho, assim como de outros tantos, e especialmente ao grupo de pesquisa Algo+ritmo por fornecer suporte teórico e experimental para esta pesquisa e para a elaboração deste artigo.

\section{REFERÊNCIAS}

Alexander, C. (1964). Notes on the synthesis of form. Cambridge, Massachusetts: Harvard University Press.

Alves, Gilfranco M. (2014). Cibersemiótica e Processos de Projeto: Metodologia em Revisão. Tese de Doutorado, USP. São Carlos - SP.

Camachoa et al. (2017). Applications of additive manufacturing in the construction industry: a prospective review. Conference: 35th International Symposium on Automation and Robotics in Construction, ISARC.

Corrêa, Natália A. (2019). Eco-Poiesis: Desenvolvimento de um Laboratório de Pesquisa Utilizando Contour Crafting. Monografia, UFMS. Campo Grande - MS.

Dotta, N. (2020). A percepção de consumidores de taipa de pilão. Campo Grande - MS, Brasil. Dissertação (Mestrado): Universidade Federal de Mato Grosso do Sul.

Estevez, A. (2003). Arquitecturas Genéticas. In: ESARQ-UIC, Santa Fe (USA). Barcelona: Lumen.

Fernandes, G.; Feitosa, L. (2015). Impact of Contour Crafting on Civil Engineering. International Journal of Engineering Research \& Technology (IJERT), Vol. 4 Issue 08, p. 628-632, Ago.

Khoshnevis, B. et al. (2006). Mega-scale fabrication by Contour Crafting. International Journal of Industrial and Systems Engineering, January,

King, H.; Ocko, S.; Mahadevan, L. (2015). Termite mounds harness diurnal temperature oscillations for ventilation. PNAS: National Academy of Sciences.

Kolarevic, B. (2003). Architecture in the Digital Age: Design and Manufacturing. Spon Press, New York. 2003.

Kontovourkis, O; Tryfonos, G. (2018). Integrating Parametric Design with Robotic Additive Manufacturing for 3D Clay Printing: An Experimental Study. Conference: 35th
International Symposium on Automation and Robotics in Construction, ISARC, p. irreg, Jul.

Kotnik, T. (2006). Algorithmic Extension of Architecture. In: MAS, ETH, ARCH/CAAD. Zurich.

Kotnik, T. (2010). Digital Architectural: Design as Exploration of Computable Functions. In: International Journal of Architectural Computing, vol. 8, $n^{\circ} 1$.

Leach N., Carlson, a., Khoshnevis B., et al. (2012). Robotic Construction by Contour Crafting: The Case of Lunar Construction. In: International Journal of Architectural Computing, vol. 10 , n. 3, p. 423-438

Leach, N. (2009) Digital Morphogenesis. In: Architectural Design Special Issue: Theoretical Meltdown, vol. $79, \mathrm{n}^{\circ} 1$, Londres: John Wiley \& Sons, p. 32-37. January.

New Story Charity. (2020). Introducing the world's first community of 3D printed homes. Retrieved from https://newstorycharity.org/3d-community/

Orciuoli, A., Celani, G. (2010). 3D em Detalhes. In: Revista AU, p. 68-71, São Paulo, dezembro, 2010. Disponível em: $<$ http://www.fec.unicamp.br/ lapac/papers/orciuoli-celani2010.pdf>. Acesso em: <24/11/18>

Pawlyn, M. (2011). Biomimicry in Architecture. Riba Publishing.

Roudavsky, S. (2012). Towards Morphogenesis in Architecture. In: International Journal of Architectural Computing. Issue 03, volume 07 .

Sperling, D. M. (2003). Diagrama e processo: o diagrama como processo. In: VII Congresso da Sociedade Ibero-americana de Gráfica Digital, SIGRADI: Cultura Digital y Diferenciación, p. 36-39, Rosário: Universidad Nacional de Rosario

Stacey, M., Beesley, P., Hui, V. (2004). Digital Fabricators: Examining the Digital Practice of Architecture. In: AIA ACADIA Fabrication conference, Coach House Press, Toronto, Ontario.

Tedeschi, A. (2011). Parametric Architecture with Grasshopper. Brienza: Le Penseur.

Terzidis, K. (2006). Algorithmic Architecture. Burlington: Elsevier.

Vincent, B. B.; Arribart, H., Bouligandc, Y.; Sanchez, C. (2002) Chemists and the school of nature. In: New Journal of Chemistry, vol. 26.

WASP. (2018). The first 3D printed House with earth | Gaia. Retrieved from https://www.3dwasp.com/en/3d-printedhouse-gaia/

Weinstock, M. (2006). Self-organisation and material constructions. In: Techniques and Technologies in Morphogenetic Design, vol 76, issue 2, p. 34-41, Londres: John Wiley \& Sons. 